\title{
AWARENESS ON PREVENTION AND CONTROL OF HIV/AIDS AMONG THE ADULTS ATTENDING AN URBAN HOSPITAL IN DHAKA
}

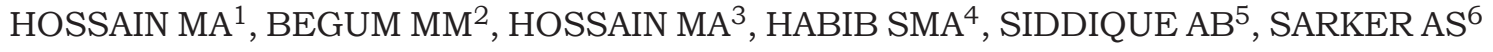

\begin{abstract}
Background: The aim the study was to evaluate the level of awareness on prevention and control of HIV/AIDS among the adults attending in an urban hospital in Dhaka city in Bangladesh.

Methods: This was a cross-sectional descriptive study done, from June, 2009 to May, 2010, among 155 adult patients at the age of 18 to 35 years in out-patient department of Dhaka Mohanagar General Hospital, Nayabazar, Dhaka. Purposive sampling technique was followed.

Results: This study showed that 46.5 percent of the adults had average knowledge about HIV/AIDS. Knowledge regarding HIV/AIDS was good in 10.3 percent cases, neither good nor bad in 27.1 percent cases and poor in 16.1 percent respondents. 54 percent of the male adults and 50.48 percent of female adults had good knowledge. Lower age (18-27 years) group adults had good knowledge about HIV/AIDS in 53 percent. The knowledge about HIV/AIDS was good in 53.97 percent of literate group. The married adults had good knowledge in 50.85 percent cases. In the employed group, 55.17 percent had good knowledge about HIV/AIDS.

Conclusion: Majority of the adults had more or less considerable knowledge on prevention and control of HIV/AIDS irrespective of gender, age, literacy, employment and educational qualification. Therefore, prevention of HIV/AIDS is possible through awareness and behavioral changes irrespective of socio-demographic variables.
\end{abstract}

Key words: HIV/AIDS, Injecting drug users, Awareness, Prevention and control.

J Dhaka Med Coll. 2014; 23(1) : 78-83.

\section{Introduction:}

Bangladesh with a population of about 158 million is one of the most densely populated countries in the world ${ }^{1}$. In Bangladesh the first case of HIV was detected in 1989. The total number of HIV infected person was 1745 up to the year of 2009. The number of patients suffering from AIDS was 619. The newly AIDS patients were 143 in number and newly infected were 250 in the year 2009. The death from AIDS was 204 in number till 2009 and 39 died in this year. HIV prevalence in general population is still $<0.1$ percent. Concentrated epidemic among the IDUs at certain areas of Dhaka city is 7.0 percent. Total number of IDUs and prostitutes are 40,000 and 90,000 at present. It reveals Bangladesh at a crossroad ${ }^{2}$.

A national baseline HIV/AIDS survey among young people aged 15-24 years established that the STI disease burden was high among them. Approximately 25 percent of males and 21 percent of females in the surveyed population reported symptoms of sexually transmitted infections (STIs). Young men and women do not perceive themselves to be at risk of acquiring STI/HIV due to lack of awareness and rampant misconception regarding the transmission and prevention of STIs. Lack of knowledge on STI symptoms and consequent delays in care-seeking behavior increases their risk towards $\mathrm{HIV}^{3}$.

1. Dr. Md. Azmal Hossain, Director, Dhaka Mohanagar General Hospital, Dhaka City Corporation, Dhaka.

2. Dr. Mosammat Makshuda Begum, Associate Professor, Department of Anaesthesiology, The Medical College for Women \& Hospital, Uttara, Dhaka.

3. Dr. Md. Akram Hossain, Medical officer, Dhaka Mohanagar General Hospital, Dhaka City Corporation, Dhaka.

4. Dr. SM Ahsanul Habib, Registrar, Department of Anaesthesiology, Apollo Hospitals, Dhaka.

5. Dr. Abu Bakar Siddique, Assistant Professor, department of medicine, Faridpur Medical College, Faridpur 6. Dr. Abdus Sattar Sarker, Assistant Professor, Department of Medicine, Sir Salimulla Medical College, Dhaka Correspondence : Dr. Md. Azmal Hossain, Director, Dhaka Mohanagar General Hospital, Dhaka City Corporation, Dhaka. 
There are several factors that make Bangladesh vulnerable to an HIV epidemic. The country is geographically situated in close proximity to India and Myanmar, which have a high HIV prevalence, and Nepal which has a concentrated HIV epidemic among IDUs. Open borders, sex industry, links between high risk groups and bridging populations, labour migration, gender inequities, poverty, low literacy levels, gaps in healthcare delivery and low levels of HIV/AIDS awareness have also been identified as important factors in the spread of HIV infection ${ }^{4}$. A set of Millennium Development Goals (MDGs) is an UN declaration on 2000 in New York, represented by 189 countries. MDGs place health at the heart of development. Three of eight goals are directly related with health, of which sixth one is to combat HIV/AIDS, malaria and other diseases. Goals have to be achieved by 2015 or earlier outlining progress from 1990. To tackle HIV/AIDS, prevention is the most effective and cheapest way. Prevention of HIV/AIDS is possible through awareness and behavioral changes. The present study is therefore conducted to assess the level of awareness on prevention and control of HIV/AIDS among the adults and to relate the socio-demographic characteristics of the adults with the level of awareness.

\section{Methods:}

This was a cross-sectional descriptive study done from June, 2009 to May, 2010 among the adult patients at the age of 18 to 35 years in the out-patient department of Dhaka Mohanagar General Hospital, under Dhaka City Corporation, Nayabazar, Dhaka. Purposive sampling technique was followed until the desired number of sample met. Sample size was calculated by applying the following formula with accuracy level at $5 \% ; \mathbf{n}=\mathbf{z}^{2} \mathbf{p q} / \mathbf{d}^{2}$ (where, $z=1.96, p=0.77$ (Awareness about HIV/AIDS among the adults about 77 percent) ${ }^{2}, q=1-p$ $=1-0.77=0.23, \mathrm{~d}=.05, \mathrm{CL}=95 \%, \mathrm{n}=$ Sample size).

Hence, eventual sample size, $n=272$. However, our feasible sample size was 155 .

A semi-structured interview questionnaire was developed according to the specific objectives. Two principal forms were used- the open-ended questions and closed- ended questions. Then information were categorized in a five point scale, as very good $=5$, good $=4$, neither good nor bad $=3$, average $=2$, and poor $=1$. Each of the respondent's answer was marked as graded in the questionnaire. The total marks of each individual got divided by the total number of questions. The average mark was calculated for each individual regarding his knowledge. Recoding was made about the value of five point scale for each individual in the following manner:

1-1.9 indicated poor knowledge and 2-5 indicated good knowledge.

The adults against each of the sociodemographic variables was divided into two groups like male and female, lower age (18-27 years) and higher age (28-35 years) groups, literate and illiterate, married and unmarried $\&$ employed and unemployed groups.

Data analysis was done by SPSS version 13.0. Chi-square test was done as the significance of the findings were tested.

\section{Results:}

Among the adults, 105 (67.7\%) were female and $55(32.3 \%)$ were male. Majority of the adults belonged to $26-30$ years age group $(41.9 \%)$ (Table-I). The percentages of literate and illiterate population were 81.3 percent and 18.7 percent respectively (Table-II). Among the adults, 72.9 percent were married, 23.9 percent were unmarried, 1.9 percent widow and 1.3 percent divorced (Table-III). Most (42.6\%) of the adults were housewives, the service holders were $36.1 \%$, the businessmen were $11 \%$, the day labors were $6.5 \%$ and the farmer was $0.6 \%$. The unemployed adults were $3.2 \%$ only (TableIV). $46.5 \%$ of the adults had average knowledge about HIV/AIDS. Knowledge regarding HIV/ AIDS was good in $10.3 \%$ cases, neither good nor bad in $27.1 \%$ cases and poor in $16.1 \%$ respondents (Table-V). $54.0 \%$ of the male population and $50.48 \%$ female population had good knowledge about HIV/AIDS, The male adults had more knowledge than female (TableVI). $53.0 \%$ of lower age (18-27years) group and $49.9 \%$ of higher age (28-35 years) group had 
good knowledge. The adults of lower age (18-27 years) group had more knowledge than the adults of higher age (28-35 years) group (TableVII). $46.3 \%$ of literate group and $58.62 \%$ of illiterate group had poor knowledge regarding HIV/AIDS. On the other hand, $53.97 \%$ of literate group and $41.38 \%$ of illiterate group had good knowledge. The adults of literate group had more knowledge than the adults of illiterate group (Table-VIII). 54.05\% of unmarried group and $50.85 \%$ of married group had good knowledge. The adults of unmarried group had more knowledge than the adults of married group (Table-IX). $47.06 \%$ of unemployed group and $55.17 \%$ employed group had good knowledge. The adults of employed group had more knowledge than the adults of unemployed group (Table-X).

Table-I

Distribution of the adults by their different age groups

\begin{tabular}{lcccccc}
\hline Age Group & \multicolumn{2}{c}{ Male } & \multicolumn{2}{c}{ Female } & \multicolumn{2}{c}{ Total } \\
& No. & $(\%)$ & No. & $(\%)$ & No & $(\%)$ \\
\hline $18-20$ years & 12 & $(7.7)$ & 27 & $(17.4)$ & 39 & $(25.2)$ \\
$21-25$ years & 15 & $(9.7)$ & 34 & $(21.9)$ & 49 & $(31.6)$ \\
$26-30$ years & 22 & $(14.2)$ & 43 & $(27.7)$ & 65 & $(41.9)$ \\
$31-35$ years & 1 & $(0.6)$ & 1 & $(0.6)$ & 2 & $(1.3)$ \\
\hline Total & 50 & $(32.3)$ & 105 & $(67.7)$ & 155 & $(100.0)$ \\
\hline
\end{tabular}

* Mean: 24.8 (SD \pm 4.3) years.

Table-II

Distribution of the adults by their education

\begin{tabular}{lcccccc}
\hline Educational & \multicolumn{2}{c}{ Male } & \multicolumn{2}{c}{ Female } & \multicolumn{2}{c}{ Total } \\
Status & No. & $(\%)$ & No. & $(\%)$ & No & $(\%)$ \\
\hline Illiterate & 3 & $(1.93)$ & 26 & $(16.77)$ & 29 & $(18.70)$ \\
Non formal education & 1 & $(0.64)$ & 1 & $(0.64)$ & 2 & $(1.29)$ \\
Primary level & 9 & $(5.80)$ & 24 & $(15.48)$ & 33 & $(21.29)$ \\
Secondary level & 30 & $(19.35)$ & 40 & $(25.80)$ & 70 & $(45.16)$ \\
HSC level & 4 & $(2.58)$ & 7 & $(4.51)$ & 11 & $(7.09)$ \\
Graduation \& above & 1 & $(0.64)$ & 6 & $(3.87)$ & 7 & $(4.51)$ \\
Others & 2 & $(1.29)$ & 1 & $(0.64)$ & 3 & $(1.93)$ \\
Total & 50 & $(32.25)$ & 105 & $(67.74)$ & 155 & $(100.0)$ \\
\hline
\end{tabular}

Table-III:

Distribution of the adults by their marital status

\begin{tabular}{lcc}
\hline Marital status & Frequency & Percentage \\
\hline Unmarried & 37 & 23.9 \\
Married & 113 & 72.9 \\
Divorced & 2 & 1.3 \\
Widow & 3 & 1.9 \\
\hline Total & 155 & 100.0 \\
\hline
\end{tabular}

Table-IV

Distribution of the adults by their main occupation

\begin{tabular}{lcc}
\hline Occupation & Frequency & Percentage \\
\hline Unemployed & 5 & 3.2 \\
Day labor & 10 & 6.5 \\
Agriculture & 1 & 0.6 \\
Business & 17 & 11.0 \\
Government service & 26 & 16.8 \\
Private service & 29 & 18.7 \\
NGO worker & 1 & 0.6 \\
House wife & 66 & 42.6 \\
\hline Total & 155 & $(100.0)$ \\
\hline
\end{tabular}


Table-V

Distribution of the adults by their knowledge regarding HIV/AIDS

\begin{tabular}{lcc}
\hline Knowledge Regarding HIV/AIDS & Frequency & Percentage \\
\hline Poor & 25 & $(16.1)$ \\
Average & 72 & $(46.5)$ \\
Neither Good nor bad & 42 & $(27.1)$ \\
Good & 16 & $(10.3)$ \\
\hline Total & 155 & $(100.0)$ \\
\hline
\end{tabular}

Table-VI

Relationship between sex and knowledge of the adult patients regarding HIV/AIDS

\begin{tabular}{|c|c|c|c|c|c|c|c|c|}
\hline \multirow{3}{*}{ Sex } & \multicolumn{6}{|c|}{ Knowledge about HIV/AIDS } & \multirow[b]{3}{*}{$\chi^{2}$} & \multirow[b]{3}{*}{$\mathrm{P}$} \\
\hline & \multicolumn{2}{|c|}{ Total } & \multicolumn{2}{|c|}{ Poor Knowledge } & \multicolumn{2}{|c|}{ Good Knowledge } & & \\
\hline & No. & $(\%)$ & No. & $(\%)$ & No. & (\%) & & \\
\hline Male & 50 & $(32.25)$ & 23 & $(46.0)$ & 27 & $(54.0)$ & & \\
\hline Female & 105 & (67.74) & 52 & $(49.52)$ & 53 & $(50.48)$ & $0.168^{*}$ & 0.682 . \\
\hline Total & 155 & & 75 & $(48.39)$ & 80 & (51.61) & & \\
\hline
\end{tabular}

* Pearson Chi-Square with two tail significance.

\section{Table-VII}

Relationship between age and knowledge of the patients regarding HIV/AIDS

\begin{tabular}{|c|c|c|c|c|c|c|c|c|}
\hline \multirow{3}{*}{ Age Group } & \multicolumn{6}{|c|}{ Knowledge about HIV/AIDS } & \multirow[b]{3}{*}{$x^{2}$} & \multirow[b]{3}{*}{$\mathrm{P}$} \\
\hline & \multicolumn{2}{|c|}{ Total } & \multicolumn{2}{|c|}{ Poor Knowledge } & \multicolumn{2}{|c|}{ Good Knowledge } & & \\
\hline & No. & $(\%)$ & No. & $(\%)$ & No. & $(\%)$ & & \\
\hline $\begin{array}{l}\text { Lower age } \\
\text { (18-27 years) }\end{array}$ & 100 & $(64.51)$ & 47 & $(47.0)$ & 53 & $(53.0)$ & $0.089^{*}$ & 0.766 \\
\hline $\begin{array}{l}\text { Higher age } \\
\text { (28-35years) }\end{array}$ & 55 & $(35.48)$ & 28 & $(50.91)$ & 27 & $(49.9)$ & & \\
\hline Total & 155 & & 75 & $(48.39)$ & 80 & $(51.61)$ & & \\
\hline
\end{tabular}

* Pearson Chi-Square with two tail significance.

Table-VIII

Relationship between literacy and knowledge of the adult patients regarding HIV/AIDS

\begin{tabular}{|c|c|c|c|c|c|c|c|c|}
\hline \multirow{3}{*}{ Literacy } & \multicolumn{6}{|c|}{ Knowledge about HIV/AIDS } & \multirow[b]{3}{*}{$\chi^{2}$} & \multirow[b]{3}{*}{$\mathrm{P}$} \\
\hline & \multicolumn{2}{|c|}{ Total } & \multicolumn{2}{|c|}{ Poor Knowledge } & \multicolumn{2}{|c|}{ Good Knowledge } & & \\
\hline & No. & $(\%)$ & No. & $(\%)$ & No. & $(\%)$ & & \\
\hline Illiterate & 29 & $(18.71)$ & 17 & $(58.62)$ & 12 & (41.38) & $1.496^{*}$ & 0.221 \\
\hline Literate & 126 & $(81.29)$ & 58 & $(46.3)$ & 68 & $(53.97)$ & & \\
\hline Total & 155 & & 75 & $(48.39)$ & 80 & $(51.61)$ & & \\
\hline
\end{tabular}

* Pearson Chi-Square with two tail significance. 
Table-IX

Relationship between marital status and knowledge of the adult patients regarding HIV/AIDS

\begin{tabular}{lcccccccc}
\hline \multirow{2}{*}{ Marital Status } & \multicolumn{7}{c}{ Knowledge about HIV/AIDS } & \\
\cline { 2 - 7 } & No. & $(\%)$ & No. & $(\%)$ & No. & $(\%)$ & $\chi^{2}$ & P \\
\hline Unmarried & 37 & $(23.87)$ & 17 & $(45.94)$ & 20 & $(54.05)$ & $0.116^{*}$ & 0.733 \\
Married & 118 & $(76.13)$ & 58 & $(49.15)$ & 60 & $(50.85)$ & & \\
Total & 155 & & 75 & $(48.39)$ & 80 & $(51.61)$ & & \\
\hline
\end{tabular}

* Pearson Chi-Square with two tail significance.

Table-X

Relationship between employment and knowledge of the adult patients regarding HIV/AIDS

\begin{tabular}{|c|c|c|c|c|c|c|c|c|}
\hline \multirow{3}{*}{ Employment } & \multicolumn{6}{|c|}{ Knowledge about HIV/AIDS } & \multirow[b]{3}{*}{$x^{2}$} & \multirow[b]{3}{*}{$\mathrm{P}$} \\
\hline & \multicolumn{2}{|c|}{ Total } & \multicolumn{2}{|c|}{ Poor Knowledge } & \multicolumn{2}{|c|}{ Good Knowledge } & & \\
\hline & No. & $(\%)$ & No. & $(\%)$ & No. & $(\%)$ & & \\
\hline Unemployed & $68(43.87)$ & 36 & $(52.94)$ & 32 & $(47.06)$ & $1.006^{*}$ & 0.316 & \\
\hline Employed & $87(56.13)$ & 39 & (44.83) & 48 & $(55.17)$ & & & \\
\hline Total & 155 & & 75 & (48.39) & 80 & (51.61) & & \\
\hline
\end{tabular}

* Pearson Chi-Square with two tail significance.

\section{Discussion:}

The general objectives of this study were to assess the level of awareness on prevention and control of HIV/AIDS. This study showed that 46.5 percent of the adults had average knowledge about HIV/AIDS. Knowledge regarding HIV/AIDS was good in 10.3 percent cases, neither good nor bad in 27.1 percent cases and poor in 16.1 percent of respondents. This result is consistent with other national study $^{2}$. In consideration of knowledge about HIV/AIDS, 54 percent of the male adults and 50.48 percent of female adults had good knowledge. Our result is consistent with national and international studies ${ }^{3-7}$. Low age (18-27 years) group adults had good knowledge about HIV/AIDS in 53 percent and poor knowledge in 47.0 percent. On the other hand, the knowledge about HIV/AIDS in high age (2835years) group was good in $49.09 \%$ and poor in $50.91 \%$ cases. Our study is comparable with international studies ${ }^{7-9}$. The knowledge about HIV/AIDS was good in 53.97 percent of literate group and poor in 46.03 percent. In illiterate group, good knowledge was in 41.38 percent and poor knowledge in 58.62 percent. The studies ${ }^{10-}$ 12 regarding HIV/AIDS awareness and attitude showed that study done is consistent both nationally and internationally. Regarding knowledge about HIV / AIDS, the married adults had good knowledge in 50.85 percent cases. In comparison to married group, unmarried group had good knowledge in 54.0 percent cases. In comparison to other studies ${ }^{7,12}$, our study is relevant with international studies.

The distribution of adults by their knowledge in respect of employment in service showed that in the employed group, 55.17 percent had good knowledge about HIV/AIDS and 54.83 percent had poor knowledge. In the other respect, in unemployed group 47.06 percent had good knowledge and 52.94 percent had poor knowledge. Our study result is partially relevant with other national study ${ }^{10}$.

\section{Conclusion:}

In consideration of knowledge regarding awareness on prevention and control HIV/ AIDS, the male adults were more aware of the 
disease than the female. The lower age (18-27 years) group was more knowledgeable about HIV/AIDS than the higher age (28-35 years) group. In comparison to illiterate adults, literate adults had good knowledge about HIV/ AIDS. The employed portion of the adults had more knowledge about HIV/AIDS than the unemployed group. The unmarried group of the adults ranks top most among the knowledgeable respondents in comparison to the married group.

Reviewing the overall findings, it was concluded that majority of the adults had more or less considerable knowledge on prevention and control of HIV/AIDS irrespective of gender, age, literacy, employment and educational qualification. Therefore, prevention of HIV/ AIDS is possible through awareness and behavioral changes irrespective of sociodemographic variables.

\section{References:}

1. National AIDS/STD Programme (NASP) Ministry of Health and Family Welfare, Government of the People's Republic of Bangladesh (Bangladesh HIV data 2009).

2. World AIDS Day, 1 December, 2009. National AIDS/STD Programme, Health Directorate, Ministry of Health and Family Welfare, Dhaka, Bangladesh. Available from http:// www.bdnasp.net/ images/bangladesh_hiv_data_ 2009.pdf [accessed on 11 March, 2011].

3. Baseline HIV/AIDS survey among youth in Bangladesh. Dhaka, ICDDR,B: Centre for Health and Population Research Associates for Community and Population Research (ACPR), Population Council, Bangladesh, 2005.

4. National HIV Serological and Behavioral Surveillance: Bangladesh HIV surveillance-4 ${ }^{\text {th }}$ round. Dhaka, ICDDRB: Centre for Health and Population, 2002.

5. A cross sectional study of awareness on hiv aids and std among young adult of village of anand district.

6. Magnus OO, Gbakeji JO. Analysis of spatial awareness of HIV/AIDS amongst Students of Tertiary Institution in Edo State, Nigeria. EthnoMed 2009; 3(2): 153-8.

7. Sen J. awareness of AIDS control and sexual behavior of youth. J Hum Ecol 2007; 22(3): 187200 .

8. HIV/AIDS among persons aged 50 and older. CDC HIV/AIDS facts. February 2008. Available from: http: / / www.cdc.gov/hiv/ topics / over50/ resources/factsheet/ pdf/over50.pdf [accessed on 12 March, 2011].

9. USAID. Health profile: Bangladesh; April 2005, Available from: http:// www.usaid.gov/ our_work/global_health/aids / Countries / ane / bangladesh_05.pdf. [accessed on 15 March, 2011].

10. Rahman M. Male's knowledge and awareness about AIDS/STD in Rajshahi district of Bangladesh. Dhaulairi J Sociol Anthropol 2: 253-72.

11. Chatterjee G, Chakraborty I, Mitra J. Knowledge About HIV and AIDS among medical entrants - a questionnaire study. Indian J Dermatol 2001; 46(2):

12. Sobahan K, Kumar TS, Kumar GS, Kanta RK, Adarsha S, Mohammad AS, et al. HIV and AIDS awareness and attitude among males in a rural population. Indian J Com Med 2004; 29(3): . 